\title{
Cooling the intact loop of primary heat transport system using Shutdown Cooling System in case of LOCA events
}

\author{
Diana Laura Icleanu*, Ilie Prisecaru, and Iulia Nicoleta Jianu \\ Polytechnic University of Bucharest, Splaiul Independentei, nr. 313, Bucharest, 060042, Romania
}

Received: 6 May 2015 / Received in final form: 22 September 2015 / Accepted: 14 October 2015

Published online: 11 December 2015

\begin{abstract}
The purpose of this paper is to model the operation of the Shutdown Cooling System (SDCS) for CANDU 6 nuclear power plants in case of LOCA accidents, using Flowmaster calculation code, by delimiting models and setting calculation assumptions, input data for hydraulic analysis and input data for calculating thermal performance check for heat exchangers that are part of this system.
\end{abstract}

\section{Introduction}

Power and energy industries have their unique challenges but they all need to rely on the efficient running of their piping systems and, therefore, optimum design and continual effective maintenance are essential. The ability to ensure accurate delivery of a product and raw materials, especially over long distances and significant elevation changes, is vital to the overall operation and success of a process plant. For such analysis, Flowmaster is a useful code. This code has been applied for analyzing the systems of CANDU reactors due to the user's possibility of defining the incompressible and compressible fluids and also the solid materials based on thermodynamic and thermophysical properties of these materials [1] stored in the corresponding generic database of the program.

Considering this, the following paper has analyzed the failure operation modes in case of loss of coolant accidents (LOCA), described in the design documentation.

The first chapter of the study provides an overview of the Shutdown Cooling System (SDCS) and an overview of the operating regimes of the system. In this section, general considerations and aspects of nuclear safety related to the LOCA accidents are also presented.

Furthermore, modeling the operation of the SDCS is performed using Flowmaster [2], by delimiting the models and developing supportable computing assumptions of the geometric configuration. It also requires introducing the input data and the calculation assumptions for the hydraulic analysis and for the thermal calculation in order to verify the functioning of the heat exchangers that are part of this system.

*e-mail: icleanud@router. citon.ro
Abnormal operating conditions [3] for the SDCS were analyzed using Flowmaster [4] calculation code and a comparison of the results was made with data obtained from a series of models developed in Pipenet.

From the results of the thermal-hydraulic analysis and the comparison with data from the compilings performed with Pipenet, it was found that in all operating conditions of the system, in case of a LOCA type accident, performance requirements specified in the design documentation are confirmed by the analysis. After modeling the SDCS, its functionality was demonstrated by achieving the required performance.

\section{Overview of the Shutdown Cooling System and the computer code used for analysis}

The SDCS is provided for cooling the Primary Heat Transport System (PHTS) from $177^{\circ} \mathrm{C}$ to $54^{\circ} \mathrm{C}$ and holding the system at $54^{\circ} \mathrm{C}$ for an indefinite period of time.

During normal operation with the reactor at power, the SDCS is kept full with heavy water at $38^{\circ} \mathrm{C}\left(100^{\circ} \mathrm{F}\right)$ temperature and a pressure equal to or just above atmospheric pressure. Figure 1 reveals the simplified network of the SDCS coupled with the PHTS in normal operation.

There are two cool down options available. The initial phase of both options is similar and involves the use of the CSDVs (Condenser Steam Discharge Valves) to lower the PHTS temperature from $260^{\circ} \mathrm{C}$, at the rate of $2.8^{\circ} \mathrm{C} / \mathrm{min}$. During this phase, the PHTS pumps circulate the coolant through the steam generators. If the SDCS pumps are to be used in the next cool down phase, the PHTS temperature first has to be brought down to $149^{\circ} \mathrm{C}$ by means of the CSDVs. Cool down to $54^{\circ} \mathrm{C}$ at the rate of $2.8^{\circ} \mathrm{C} / \mathrm{min}$ is 


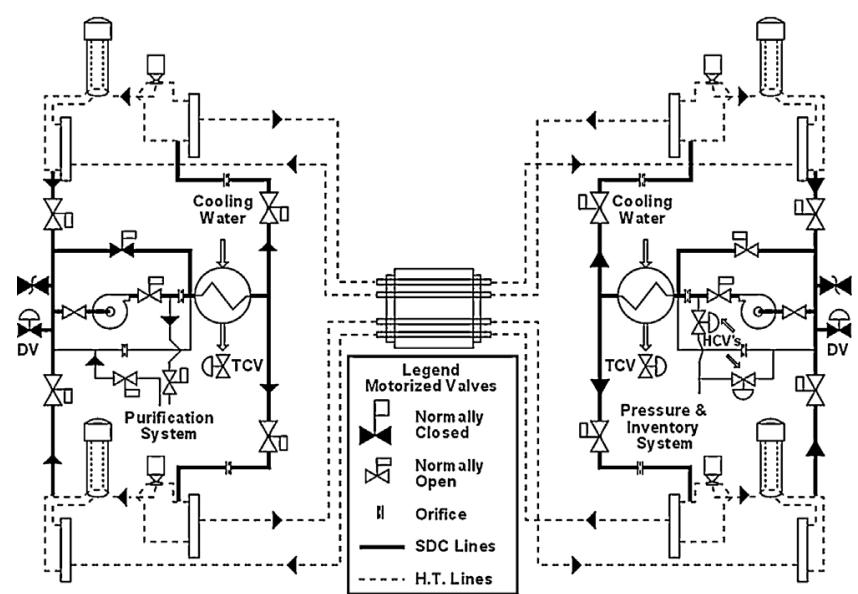

Fig. 1. Simplified network of SDCS coupled with PHTS. (Source: https://canteach.candu.org/Content\%20Library/19930204.pdf).

carried out using the SDCS pumps and heat exchangers (HX).

\subsection{Operating the SDCS in case of LOCA}

Following a large LOCA, with or without Class IV power, the SDCS is required to cool the PHTS intact loop. For the first 900 seconds ( 15 minutes), upon receipt of the LOCA signal, the Moderator Temperature Control (MTC) program controls the "moderator rapid cool down". Following the first 900 seconds after LOCA, the recirculated cooling water flow rate of $200 \mathrm{~L} / \mathrm{s}$ is made available to the SDCS by limiting the opening of the large temperature control valves (an MTC program action) to limit the flow towards the heat exchangers.

In this case, in order to cool down the PHTS intact loop, the operator has to bring in the SDCS manually, following a large LOCA, which will act as a backup heat sink for the thermo-siphoning of the intact loop [5].

This paper analyses the case of cooling the intact loop of the PHTS, using the SDCS, 15 or 30 minutes after the initiation of LOCA, using both the pumps and the heat exchangers of the SDCS or only one pump and one heat exchanger (Class IV or Class III available) [6].

LOCA [7] are the most severe challenges for all security systems, requiring that they operate at the best performance levels.

\subsection{Fundamentals in Flowmaster}

For the development of the thermal-hydraulic analysis of the SDCS, the computing program Flowmaster was used, a one-dimensional thermal-hydraulic calculation code for dimensioning, analyzing and verifying the operation of the pipeline systems.

This code provides a graphical virtual working environment and enables the design, redefinition and test of the whole fluid flow system.

Steady state or transient modules of Flowmaster code for single-phase fluids were designed specifically in order to model the heat transfer effects in many application areas. The modules enable users to develop transient analysis for such kind of events.

Each component of Flowmaster is a mathematical model for a piece of equipment that is included in a facility.

Selected components are connected via nodes in order to form a network which constitutes a computerized model of the system.

A Flowmaster network contains a number of components (pipes, tubing, pumps, fans, flow and pressure sources, etc.) and the links between them.

The points in which components are linked to one another are called nodes.

When a network is prepared for simulation, each component and node must have a unique label. Filling the entire schematic representation (Flowmaster network) is an essential part of any simulation.

The nodal diagram (Flowmaster network) achieved consisted of a sequence of segments separated by nodes, which represent portions of pipe trails sections, without diameter or branch variations along them. Various equipments or components (except for retaining tabs) are represented by pressure loss coefficients.

For simulating using Flowmaster code, the heavy water flow in the SDCS in order to determine the variation of pressure and flow at various points of the circuit, a nodal scheme - Flowmaster network was done.

The Flowmaster computing code [8] was verified with an exact calculation on the thermal part of the analysis and with Pipenet program on the hydraulic part of it.

\section{Application of Flowmaster code in thermal- hydraulic analysis of the SDCS}

\subsection{Models and computing hypotheses}

In order to develop the thermal-hydraulic analysis of the SDCS in case of LOCA, the following calculation models that cover the requirements of the design theme were done.

\subsubsection{Model I}

Hydraulic calculation model for the SDCS, when operating under a LOCA failure mode, model in which the cooling of the PHTS is started at $177^{\circ} \mathrm{C}$ using heat exchangers, HX1 and HX2, to provide the cold source, while the circulation will be maintained by the SDCS pumps, P1 and P2.

\subsubsection{Model II}

Hydraulic calculation model for the SDCS, when operating under a LOCA failure mode, model in which the cooling of the PHTS is started at $177^{\circ} \mathrm{C}$ using one heat exchanger, HX1 or HX2, to provide the cold source, while the circulation will be maintained by one of the SDCS pumps, P1 or P2. 


\subsubsection{Model III}

Thermal calculation model for the heat exchangers, HX1 and HX2, related to the SDCS, when the SDCS is operating in failure mode. In this case the heat exchangers HX1 and HX2 are cooled with water flow coming from the intermediate cooling water system. The inlet temperature considered on the secondary side of the heat exchangers is $30{ }^{\circ} \mathrm{C}$. In model III, the SDCS is working with its associated pumps, P1 and P2.

\subsubsection{Model IV}

Thermal calculation model for the heat exchangers, HX1 and HX2, related to the SDCS, when the SDCS is operating in failure mode. The heat exchangers HX1 and HX2 are also cooled with water flow coming from the intermediate cooling water system. The difference between model III and model IV is that the inlet temperature on the secondary side of the heat exchangers is $35^{\circ} \mathrm{C}$. In model IV, the SDCS is working with both SDCS pumps.

\subsubsection{Model V}

Thermal calculation model for the heat exchangers, related to the SDCS, when the SDCS is operating in failure mode (in which case only one pump and one heat exchanger related to the SDCS are used). For this case, the inlet temperature on the secondary side of the heat exchangers is $30^{\circ} \mathrm{C}$.

\subsubsection{Model VI}

Thermal calculation model for the heat exchangers related to the SDCS, when the SDCS is operating in failure mode (in which case they only use one pump and one heat exchanger related to the SDCS). The inlet temperature on the secondary side of the heat exchangers according to the manual design of the cooling water system is $35^{\circ} \mathrm{C}$.

For the considered analysis, a set of design assumptions were made. For the hydraulic analysis, the hypotheses are as follows:

- system condition at the baseline of cooling is a state of stationary hydraulic regime;

- hydraulic resistances of PHTS lines are determined taking into account the pressure drop values on these lines, for the nominal operating regime;

- hydraulic resistance of SDCS lines is determined taking into account the dimensional characteristics and their composition (the fittings on these lines);
- pumps that do not work are modeled as lines with hydraulic resistance determined from the characteristic curves for the respective pumps;

- for the heat exchangers and steam generators we consider only the primary circuit, that is modeled as a pipeline with the hydraulic resistance;

- pressure in the system is fixed at one of the output collectors of the reactor by boundary condition;

- interfaces with other systems were neglected, connecting pipes to these systems are not functional for the analyzed regimes.

Assumptions considered for the thermal analysis were also set as follows:

- the energy accumulated in metal tubes and shell is neglected;

- the compressibility of the fluids is neglected;

- in the shell and in the heat exchanger's tubes, the flow is single phase;

- the initial thermal condition is that the temperature in the entire system is considered to be the same;

- the paper does not take into account the preparatory steps aimed at achieving either of the necessary cooling configurations, thus neglecting transient hydraulic regimes preceding the making of either of the cooling schemes analyzed.

For the accomplishment of the hydraulic calculation with the help of the calculating code Flowmaster V7, pressure values have been entered, corresponding to hydrostatic pressure determined at the output collector of the reactor by boundary conditions.

Thus, for all hydraulic calculation models the appropriate pressure values for the inlet/outlet components of the nodal scheme were considered according to Table 1.

\subsection{Description of collected data and output files}

Output files for the thermo-hydraulic calculation with the Flowmaster program are structured according to the type of simulation (hydraulic or thermal) as follows:

- hydraulic calculation results for each component (flow, velocity, Reynolds number, pressure loss, etc.);

- hydraulic calculation results in each node (pressure);

- thermal calculation results suitable for components in which heat transfer occurs (thermal load, overall heat transfer coefficient, temperature difference between input and output);

- thermal calculation results in each node (temperature).

Results can be filtered by type of component or by characteristic parameters calculated, according to the components that make up the nodal scheme.

Table 1. Boundary conditions for the hydraulic analysis.

\begin{tabular}{llll}
\hline Operation mode & Point position & Temperature $\left({ }^{\circ} \mathrm{C}\right)$ & Pressure (bar) \\
\hline Model I & Output collector from the reactor (pressure source: 314$)$ & 177 & 95 \\
Model II & Output collector from the reactor (pressure source: 314$)$ & 177 & 95 \\
\hline
\end{tabular}




\subsubsection{Model I}

Hydraulic calculation model for the operation in failure mode of the SDCS, model in which the cooling of the PHTS starts at $177^{\circ} \mathrm{C}$ using heat exchangers, HX1 and HX2 (water is circulated by SDCS's pumps, P1 and P2). According to the results, the calculated hydraulic parameter values are shown in Table 2 .

\subsubsection{Model II}

Hydraulic calculation model for the operation in failure mode of the SDCS, model in which the cooling of the PHTS starts at $177^{\circ} \mathrm{C}$ using one heat exchanger, HX1 or HX2, to provide the cold source, while the circulation will be maintained by one of SDCS's pumps, P1 or P2.

According to the results, the calculated hydraulic parameter values are listed in Table 3.

\subsubsection{Model III}

Thermal calculation model for the heat exchangers, HX1 and $\mathrm{HX} 2$, related to the SDCS, for the operation in failure mode of the SDCS. This model concerns the time evolution of the temperature in PHTS.

According to the results, the parameter values for the heat transfer of the heat exchangers HX1 and HX2, at the moment of achieving the cooling requirement for PHTS (temperature in PHTS must be $54^{\circ} \mathrm{C}$ ) are shown in Table 4.

Table 2. Hydraulic analysis. Model I.

\begin{tabular}{ll}
\hline Component & Flow rate $(\mathrm{L} / \mathrm{s})$ \\
\hline Flow through P1 SDCS & 115 \\
Flow through P2 SDCS & 114 \\
Flow through HX1 SDCS & 104 \\
Flow through HX2 SDCS & 103 \\
Flow through inlet & HD6: 104 \\
collectors HD6, HD2, HD4, HD8 & HD2: $1.4 \times 10^{-10}$ \\
& HD4: $2.27 \times 10^{-9}$ \\
Flow through outlet & HD8: 103 \\
collectors HD5, HD1, HD3, HD7 & HD5: 104 \\
& HD1: $1.85 \times 10^{-9}$ \\
& HD3: $1.73 \times 10^{-9}$ \\
Flow through P1, P2, P3, P4 PHTS & HD7: 103 \\
& P2: $1.55 \times 10^{-10}$ \\
& P3: 54 \\
Flow through fuel & P4: 54 \\
channels R1, R2, R3 and R4 & R1: $2.15 \times 10^{-10}$ \\
& R2: 50 \\
& R3: $1.79 \times 10^{-9}$ \\
& R4: 50 \\
\hline
\end{tabular}

Table 3. Hydraulic analysis. Model II.

\begin{tabular}{ll}
\hline Component & Flow rate $(\mathrm{L} / \mathrm{s})$ \\
\hline Flow through P1 SDCS & 115 \\
Flow through P2 SDCS & 1.7 \\
Flow through HX1 SDCS & 104 \\
Flow through HX2 SDCS & 1.9 \\
Flow through inlet & HD6: 104 \\
collectors HD6, HD2, HD4, HD8 & HD2: $7.75 \times 10^{-12}$ \\
& HD4: $7.3 \times 10^{-12}$ \\
Flow through outlet & HD8: 1.9 \\
collectors HD5, HD1, HD3, HD7 & HD5: 104 \\
& HD1: $4.14 \times 10^{-12}$ \\
& HD3: $4.11 \times 10^{-12}$ \\
Flow through P1,P2, P3, P4 PHTS & P1: $4.97 \times 10^{-12}$ \\
& P2: $5.2 \times 10^{-12}$ \\
& P3: 67 \\
Flow through fuel & P4: 34.8 \\
channels R1, R2, R3 and R4 & R1: $6.9 \times 10^{-12}$ \\
& R2: 36.7 \\
& R3: $5 \times 10^{-12}$ \\
& R4: 36.7 \\
\hline
\end{tabular}

Table 4. Thermal analysis. Model III.

\begin{tabular}{ll}
\hline Thermal load of SDCS HX1/HX2 & $10.99 \mathrm{MW}(\mathrm{th})$ \\
\hline $\begin{array}{l}\text { Outlet temperature for } \mathrm{D}_{2} \mathrm{O} \text { of PHTS } \\
\text { Outlet temperature for the cooling }\end{array}$ & $54.06{ }^{\circ} \mathrm{C}$ \\
water of SDCS HX1 and HX2 & \\
\hline
\end{tabular}

Figure 2 is a plot of temperature decrease of PHTS coolant for the inlet and outlet of the SDCS heat exchangers.

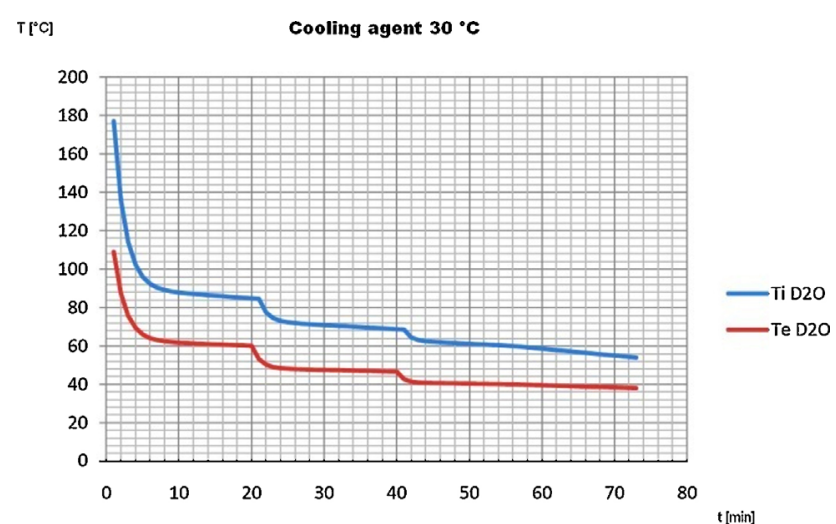

Fig. 2. Examination for $2 \mathrm{HX}$ for cooling agent $30^{\circ} \mathrm{C}$. 
Table 5. Thermal analysis. Model IV.

\begin{tabular}{ll}
\hline Thermal load of SDCS HX1/HX2 & $8.95 \mathrm{MW}(\mathrm{th})$ \\
\hline $\begin{array}{l}\text { Outlet temperature for } \mathrm{D}_{2} \mathrm{O} \text { of PHTS } \\
\text { Outlet temperature for the cooling }\end{array}$ & $54.16{ }^{\circ} \mathrm{C}$ \\
water of SDCS HX1 and HX2 & $41.32{ }^{\circ} \mathrm{C}$ \\
\hline
\end{tabular}

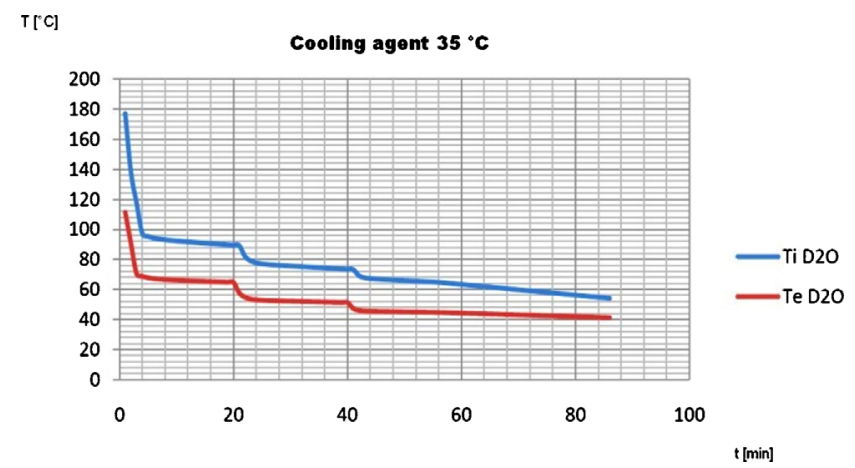

Fig. 3. Examination for $2 \mathrm{HX}$ for cooling agent $35^{\circ} \mathrm{C}$.

Table 6. Thermal analysis. Model V.

\begin{tabular}{ll}
\hline Thermal load of SDCS HX1/HX2 & $5.4 \mathrm{MW}(\mathrm{th})$ \\
\hline $\begin{array}{l}\text { Outlet temperature for } \mathrm{D}_{2} \mathrm{O} \text { of PHTS } \\
\text { Outlet temperature for the cooling }\end{array}$ & $52.43^{\circ} \mathrm{C}$ \\
water of SDCS HX1 and HX2 & $41.18^{\circ} \mathrm{C}$ \\
\hline
\end{tabular}

\subsubsection{Model IV}

Thermal calculation model for the heat exchangers, HX1 and HX2, related to the SDCS, for the operation of the SDCS under failure mode (LOCA). The inlet temperature on the secondary side of the heat exchangers is $35^{\circ} \mathrm{C}$. In model IV, the SDCS is working with its own pumps, $\mathrm{P} 1$ and P2. The results are shown in Table 5.

Figure 3 is also a plot of temperature decrease of PHTS coolant for the inlet and outlet of the SDCS heat exchangers. The difference between model III and model IV is the inlet temperature of the cooling water that passes through the heat exchangers.

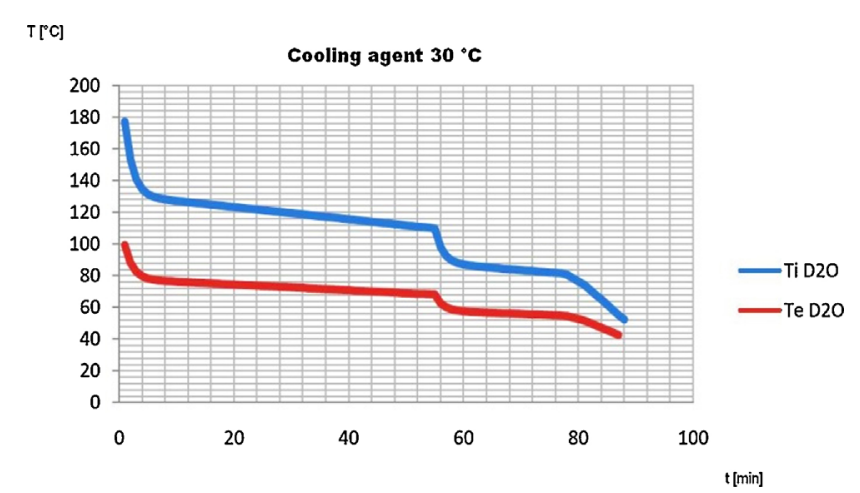

Fig. 4. Examination for $1 \mathrm{HX}$ for cooling agent $30^{\circ} \mathrm{C}$.
Table 7. Thermal analysis. Model VI.

\begin{tabular}{ll}
\hline Thermal load of SDCS HX1/HX2 & $4.17 \mathrm{MW}(\mathrm{th})$ \\
\hline Outlet temperature for $\mathrm{D}_{2} \mathrm{O}$ of PHTS & $52.2^{\circ} \mathrm{C}$ \\
$\begin{array}{l}\text { Outlet temperature for the cooling } \\
\text { water of SDCS HX1 and HX2 }\end{array}$ & $43.5^{\circ} \mathrm{C}$ \\
\hline
\end{tabular}

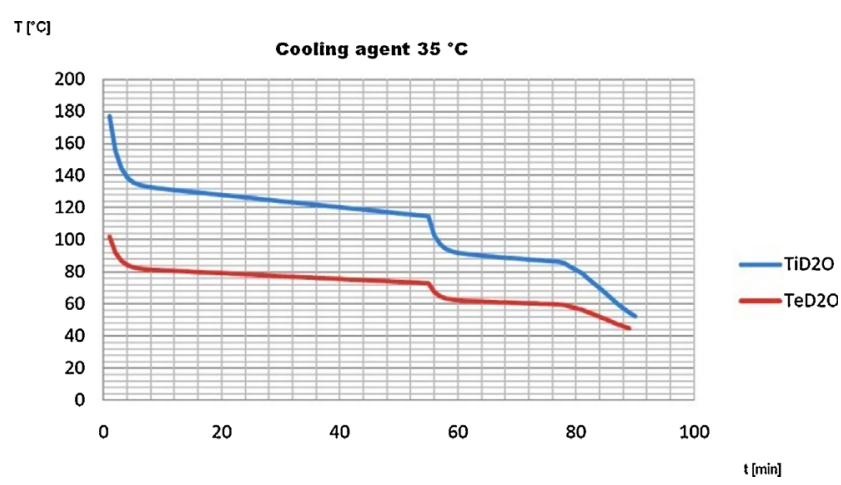

Fig. 5. Examination for $1 \mathrm{HX}$ for cooling agent $35^{\circ} \mathrm{C}$.

\subsubsection{Model V}

Thermal calculation model for the heat exchangers, HX1 or HX2, related to the SDCS, for the operation in failure mode of the SDCS (LOCA).

Table 8. Comparative results from the hydraulic analyses. Model I.

\begin{tabular}{lll}
\hline & $\begin{array}{l}\text { Data obtained } \\
\text { by using } \\
\text { Pipenet }(\mathrm{L} / \mathrm{s})\end{array}$ & $\begin{array}{l}\text { Data obtained } \\
\text { by using } \\
\text { Flowmaster }(\mathrm{L} / \mathrm{s})\end{array}$ \\
\hline Flow through P1 & 118.4 & 115 \\
Flow through P2 & 118.4 & 114 \\
Flow through HX1 & 106.6 & 104 \\
Flow through HX2 & 106.6 & 103 \\
Flow through & HD6: 106.6 & HD6: 104 \\
inlet collectors & HD2: 0 & HD2: $1.4 \times 10^{-10}$ \\
& HD4: 0 & HD4: $2.27 \times 10^{-9}$ \\
& HD8: 106.6 & HD8: 103 \\
Flow through & HD5: 106.6 & HD5: 104 \\
outlet collectors & HD1: 0 & HD1: $1.85 \times 10^{-9}$ \\
& HD3: 0 & HD3: $1.73 \times 10^{-9}$ \\
Flow through & PD7: 106.6 & HD7: 103 \\
PHTS pumps & P2: 0 & P1: $4 \times 10^{-10}$ \\
& P3: 58.6 & P2: $1.55 \times 10^{-9}$ \\
& P4: 58.6 & P3: 54 \\
Flow through & R1: 0 & R1: $2.15 \times 10^{-10}$ \\
fuel channels & R2: 53 & R2: 50 \\
& R3: 0 & R3: $1.79 \times 10^{-9}$ \\
& R4: 53 & R4: 50 \\
\hline
\end{tabular}


Table 9. Comparative results from the hydraulic analyses. Model II.

\begin{tabular}{lll}
\hline & $\begin{array}{l}\text { Data obtained } \\
\text { by using } \\
\text { Pipenet }(\mathrm{L} / \mathrm{s})\end{array}$ & $\begin{array}{l}\text { Data obtained } \\
\text { by using } \\
\text { Flowmaster }(\mathrm{L} / \mathrm{s})\end{array}$ \\
\hline Flow through P1 & 118.4 & 115 \\
Flow through P2 & 0 & 1.7 \\
Flow through HX1 & 106.6 & 104 \\
Flow through HX2 & 0.3 & 1.9 \\
Flow through & HD6: 106.6 & HD6: 104 \\
inlet collectors & HD2: 0 & HD2: $7.75 \times 10^{-12}$ \\
& HD4: 0 & HD4: $7.3 \times 10^{-12}$ \\
& HD8: 0.3 & HD8: 1.9 \\
Flow through & HD5: 106.6 & HD5: 104 \\
outlet collectors & HD1: 0 & HD1: $4.14 \times 10^{-12}$ \\
& HD3: 0 & HD3: $4.11 \times 10^{-11}$ \\
Flow through & PD7: 0.3 & HD7: 1.9 \\
PHTS pumps & P2: 0 & P1: $4.97 \times 10^{-12}$ \\
& P3: 71 & P2: $5.2 \times 10^{-12}$ \\
& P4: 35.4 & P3: 67 \\
Flow through & R1: 0 & R1: $6.9 \times 10^{-12}$ \\
fuel channels & R2: 38 & R2: 36.7 \\
& R3: 0 & R3: $5 \times 10^{-12}$ \\
& R4: 37.9 & R4: 36.7 \\
\hline
\end{tabular}

In model $\mathrm{V}$, the SDCS is working with one heat exchanger and one of the SDCS pumps, P1 or P2. Table 6 provides the main results for this case of operation mode.

Figure 4 is also a plot of temperature decrease of PHTS coolant for inlet and outlet of the SDCS heat exchangers.

\subsubsection{Model VI}

Thermal calculation model for the heat exchangers, HX1 and HX2, related to the SDCS, for the operation under failure mode of the SDCS (LOCA). In this model, the SDCS is working with one heat exchanger and one of the SDCS pumps, P1 or P2.

The inlet temperature on the secondary side of the heat exchangers is $35^{\circ} \mathrm{C}$. Table 7 shows the results of this analysis.

Figure 5 is also a diagram of the temperature decrease for PHTS coolant.

For the hydraulic analyses, two Pipenet models were considered in order to verify the results obtained in Flowmaster. The results are presented in Tables 8 and 9.

\section{Conclusions}

This paper presents a thermal-hydraulic analysis of the simultaneous operation of the SDCS and of the primary heat transport system, associated to a CANDU 6 NPP (nuclear power plant), operating in LOCA accident regime, using Flowmaster calculation code.

The modelling of heavy water flow through the SDCS and primary heat transport system was performed to determine the distribution of flow rates and pressure in various areas of the hydraulic circuit and the pressure loss corresponding to the components, but also in order to calculate the heat of the heat exchangers related to the system.

The configurations corresponding to the SDCS coupled to the primary heat transport system are in accordance with the thermo-mechanical schemes of the systems similar to those at Cernavoda NPP.

Within this work, complex hydraulic/thermo-hydraulic analyses were performed for the SDCS coupled with the primary heat transport system. Hydraulic analyzes developed using Flowmaster program aimed at the verification of the hydraulic models as well as the determination of flow and pressure loss in baseline cooling processes in degraded mode.

The results of the thermo-hydraulic analysis show that in all cases analyzed, for the LOCA accident regime, the performance requirements are satisfied according to the analysis.

The heat exchangers of the SDCS have the ability to perform the cooling of the primary heat transport system from $177^{\circ} \mathrm{C}$ to $54^{\circ} \mathrm{C}$ in approximately 79 minutes, if the inlet temperature of reactor cooling water $(\mathrm{RCW})$ is $30^{\circ} \mathrm{C}$.

After 79 minutes, the residual heat necessary to be extracted from the primary circuit by means of both heat exchangers of the SDCS is approximately $10 \mathrm{MW}$ and the thermal load of the heat exchanger is $10.99 \mathrm{MW}$.

If the inlet temperature of the $\mathrm{RCW}$ heat exchangers is $35^{\circ} \mathrm{C}$, then the cooling from $177^{\circ} \mathrm{C}$ to $54^{\circ} \mathrm{C}$ of the primary heat transport system will be made in approximately 86 minutes.

After 86 minutes, the residual heat necessary to be extracted from the primary circuit by means of a heat exchanger of the SDCS is approximately $4.85 \mathrm{MW}$ and the thermal load of the heat exchanger is $8.95 \mathrm{MW}$.

For the model in which the PHTS cooling is provided only by one of the heat exchangers of the SDCS, if the inlet temperature of the RCW heat exchangers is $30^{\circ} \mathrm{C}$, the residual heat necessary to be extracted has a value of $3.71 \mathrm{MW}$. By means of the heat exchanger having the heat load of $5.4 \mathrm{MW}$, cooling from $177^{\circ} \mathrm{C}$ to $54^{\circ} \mathrm{C}$ is achieved in approximately 88 minutes.

If the inlet temperature of the operating heat exchanger is $35^{\circ} \mathrm{C}$, then cooling from $177^{\circ} \mathrm{C}$ to $54^{\circ} \mathrm{C}$ of the primary heat transport system will be achieved in approximately 90 minutes.

After 90 minutes, the residual heat necessary to be extracted from the primary circuit by means of a heat exchanger of the SDCS is approximately $2.87 \mathrm{MW}$ and the thermal load of the heat exchanger is $4.17 \mathrm{MW}$.

As a result of this thermal analysis wherein the inlet temperature of the intermediate cooling water at the heat exchangers is $35^{\circ} \mathrm{C}$, a series of differences were observed compared to the data sheets of the heat exchangers, HX1 and HX2, namely:

- thermal load taken by the heat exchangers is smaller, but above the necessary; 
- primary heat transport system may be cooled to a temperature of $54{ }^{\circ} \mathrm{C}$, but it would take longer;

- intermediate cooling water temperature at the outlet of the heat exchanger has a higher value.

Another observation is that both in the case when two heat exchangers are operation, as well as the case with one heat exchanger, in LOCA accident regime, PHTS cooling can be achieved by using the SDCS. The only difference noticed between the two models considered is that for the operation with a heat exchanger instead of two, cooling is done in a longer but covering time.

Regarding the temperatures, a normal evolution in the PHTS cooling process is found, but it cannot be measured accurately and precisely because of the lack of information on the conditions under which the analyses were developed, as the basis for the evolution curves of the residual heat present in the reactor after 15 minutes, and 30 minutes, respectively, from the start of the accident of the coolant loss type.

By analyzing the parameters of the cooling system for all cooling processes considered, it was found that the values obtained for thermal-hydraulic parameters, as well as the duration up to reaching specified limits fall within the design values of the system. Cooling speeds are situated below the value of $2.8^{\circ} \mathrm{C} / \mathrm{min}$ at the reactor outlet for all cooling regimes in case of LOCA accidents.
The work has been funded by the Sectoral Operational Programme Human Resources Development 2007-2013 of the Ministry of European Funds through the Financial Agreement POSDRU/159/1.5/s/134398.

\section{References}

1. A. Leca, I. Prisecaru, Thermo-physical and thermodynamic properties of solid, liquid and gas (Ed. Tehnică, Bucharest, 1994)

2. D.S. Miller, Internal flow systems, 2nd edn. (Miller Innovations, 2008)

3. Nuclear Regulatory Commission, Theoretical possibilities and consequences of major accidents in large nuclear power plants. (Rep. WASH 740, US Govt Printing Office, Washington, DC, 1957)

4. Flowmaster v7, New user training, version 10

5. Requirements for the safety analysis of CANDU nuclear power plants, AECB Consultative Document C-6, 1980

6. Safety analysis: event classification, www.iaea.org

7. International Atomic Energy Agency, Incorporation of advanced accident analysis methodology into safety analysis reports, IAEA-TECDOC-1351, 2003

8. Haestad Methods Water Solutions, Computer applications in hydraulic engineering, 7th edn. (Bentley Institute Press, 2006)

Cite this article as: Diana Laura Icleanu, Ilie Prisecaru, Iulia Nicoleta Jianu, Cooling the intact loop of primary heat transport system using Shutdown Cooling System in case of LOCA events, EPJ Nuclear Sci. Technol. 1, 13 (2015) 